\title{
Enersemest \\ Ethical and legal issues raised by cord blood banking - the challenges of the new bioeconomy
}

\begin{abstract}
Cameron L Stewart BEc, LLB(Hons), PhD, Professor of Health, Law and Ethics, Centre for Health Governance Law and Ethics

Lorena C Aparicio MPE,
Manager $^{2}$

Strategic Project Manager

Ian H Kerridge

MPhil, FRACP, FRCPA,

Director and Associate

Professor of Bioethics,

Centre for Values, Ethics

and the Law in Medicine

and Staff Haematologist

and Bone Marrow

Transplant Physician

1 University of Sydney, Sydney, NSW.

2 Australian Bone Marrow

Donor Registry,

Sydney, NSW.

3 Royal North

Shore Hospital,

Sydney, NSW.

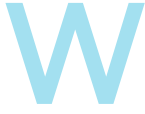

hile human tissue has always had cultural, educational and scientific value, it is only in the past 40 years that tissue economies have begun to emerge. ${ }^{1}$ These economies have been driven by advances in technology that rapidly reversed our perception of human tissue as a useless by-product of treatment, to being a valuable and powerful source of wealth. Umbilical cord blood banking is an excellent example of this trend - what once was waste is now considered to be a wonder product that is collected, stored and traded in private and public markets. ${ }^{2}$ As a consequence, cord blood stem cells have become a focus of public, medical and scientific contest because of their uncertain ontological status (whether they are simply adult stem cells or share properties of both embryonic and adult stem cells), and because they have proven value as a source of haematopoietic stem cells for transplantation and more speculative value as a source of autologous stem cells for regenerative medicine.
\end{abstract}

laparicio@abmdr.org.au

doi: 10.5694/mjal2.11668

Previously in this series

"Ethics series - 2"

in MJA 2013; 198: 496-502

Series Editor

Dominic JC Wilkinson

MBBS, DPhil, FRACP

\section{Therapy and research: proof and potential}

The benefits of cord blood stem cells in haematopoietic stem cell transplantation (HSCT) are clear. They are easily (non-invasively) collected and stored, they provide a rapidly available source of stem cells for HSCT, they extend the number of patients for whom HSCT is an option (because of their immunological immaturity), and they have been shown to give clinical outcomes equivalent to HSCT using bone marrow or peripheral blood stem cells. ${ }^{3}$ The benefits of cord blood transplantation rely primarily on the altruistic donation of cord blood around the world to an international network of more than 54 public cord blood banks, which collect, process, store and supply cord blood units (CBUs) for transplantation in Australia and internationally.

In contrast, the banking of autologous cord blood in private cord blood banks is based on the hope that it may, at some point in the future, be of therapeutic benefit in treating or curing any form of chronic or degenerative disease in its donor or in others. At present, this is entirely speculative. The likelihood that the infant, or other family members, will need access to their cord blood haematopoietic stem cells for established therapeutic indications is extremely low. For the most part, such use would be largely unnecessary, as most patients who need an autologous HSCT have haematopoietic stem cells collected from their peripheral blood or bone marrow when required. ${ }^{4}$ Despite the absence of indications for this use of cord blood, many parents elect to bank their child's cord blood as a form of biological insurance, in the belief that such benefits may be recognised in the future - or at least

\begin{abstract}
Summarv
- Cord blood banking raises ethical and legal issues which highlight the need for careful regulatory approaches to the emerging bioeconomy.

- Consent processes for both private and public banking should be inclusive and representative of the different familial interests in the cord blood.

- Property law is a potentially useful way of understanding the mechanisms for donation to both public and private banks.

- Increasing tensions between public and private models of banking may require the adoption of hybrid forms of banking.
\end{abstract}

to satisfy themselves that they have done everything in their power to guarantee their child's wellbeing. There are now 225 private cord blood banks worldwide, storing nearly 1 million CBUs, which far exceeds the estimated 600000 CBUs that are stored in publicly accessible cord blood banks. $^{5}$

The emergence and rapid growth of private cord blood banks provides a significant challenge to the viability of public cord blood banks - a challenge that is likely to grow if evidence accumulates regarding cord blood stem cells' utility in regenerative medicine. ${ }^{6}$ This challenge is both philosophical and practical. Philosophically, transplantation programs can only meet defined need and optimise equity in health care if sufficient numbers of citizens value social solidarity and make an altruistic decision to donate cord blood in the public interest. Practically, cord blood banks need to have a sufficient number of CBUs to maintain human leukocyte antigen variability, so that HSCT with sufficiently high cell doses and optimal human leukocyte antigen matching is available to those who need it. 7,8

What makes these challenges so difficult is that they reflect fundamental moral questions regarding the design and delivery of health care systems, the rights and responsibilities of citizens in liberal democracies, the commitments that we have to generational fairness, and questions concerning ownership of human tissue. While some of these ethical and legal uncertainties are specific to cord blood (due, in part, to its origins in pregnancy), others are a feature of the challenges that arise in regulating emerging tissue economies.

In Australia, cord blood banking has emerged in a regulatory vacuum, and so has come to be governed by a patchwork of common law and legislative principles, including the doctrine of informed consent, legal and ethical notions of donation, and therapeutic goods law. ${ }^{9}$ This lack of direct regulation has undoubtedly created uncertainty regarding the status and management of cord 
blood and the obligations of both public and private cord blood banks.

\section{Problems with consent: whose blood is being} banked for whom?

Standard models of tissue donation assume that the process of informed consent must involve the person from whom the tissue is being taken (in living donation), or their representative (in some types of posthumous donation). Such an assumption is problematic in cord blood banking because it is not clear whether the mother or the child is the donor. As a practical matter, most collection occurs after consent from the mother either directly or on behalf of the child - but it is not clear, legally or ethically, that this is the most appropriate way of gaining consent. While consent has not yet been a subject of disagreement in this area, it is not hard to envision, in the modern era of the blended family, that there is potential for competing family claims should the therapeutic potential of cord blood materialise. And if situations arise where competing claims are made over stored cord blood, the nature of consent to storage and issues regarding proprietary interests (discussed below) will take central place in the resolution of any conflict.

Cord blood is genetically identical to the child but, depending on the method of collection and type of birth, may be collected from the mother or child, or from the cord when neither child nor mother is connected to it. There seems to be no dominant ethical or religious position as to who the donor is. ${ }^{10}$ Nor does the law provide any direct answer, as it views the placenta/umbilicus as being part of the mother for some purposes and part of the child for others. ${ }^{2}$ If one seeks an answer via genetics, one might argue that the child has a better claim, but it might be equally argued that other family members, including the father and siblings (both present and future), have claim to the cord blood, given the shared nature of the genetic information contained within it and its potential therapeutic uses.

We argue that these complexities require the consent process to be inclusive and representative of the different family interests in the cord blood. Thus, rather than relying purely on the birth mother to give consent, the process should, where possible, include the mother's parenting partner. Further, it is our view that the consent given by the parents should expressly recognise that they are also consenting on behalf of the child.

Questions have also been raised regarding whether informed consent to private banking is a realistic possibility, given the extremely low likelihood of requiring one's own stem cells for autologous transplantation later in life and the inevitably coercive nature of any decision that rests on assumptions about the best interests of children. It has been claimed that private banks in the United States have capitalised on the chance that families will overestimate the true likelihood of needing stored cord blood. ${ }^{11}$ Indeed, some would argue that advertising these services is exploitative, given the degree to which expectant parents are open to consider anything that may benefit their child (irrespective of the realistic expectation of that benefit) and the low likelihood that the cord blood will ever be used. However, there is no evidence that Australian private cord blood banks have engaged in any form of misleading or deceptive conduct in relation to their services. Indeed, our own view of Australian private cord blood banks is that their advertising seems rather modest, raising notions of insurance and explicitly acknowledging the low chance of the family ever needing to access the cord blood. In any event, the strictures of the Australian Consumer Law would be likely to prevent misleading and deceptive advertising.

\section{Cord blood banking and property rights}

As tissue economies have emerged, the common law of property has changed to recognise that people have property rights over their human tissue. Traditionally, the common law refused to recognise property rights in human tissue, unless the tissue had been preserved through some work or skill. ${ }^{12-14}$ This rule gave the property rights to whoever provided the labour or whoever paid for it to be done, which in the cord blood context gave rights to the public banks and to the purchasers of the services of the private banks. However, in the past 2 years, courts in both the United Kingdom and Australia have begun to recognise property rights in tissue that are not dependent on the work and skill exception, giving rise to rights to its possession, use, bailment (a property relationship), and protection from negligent storage. ${ }^{15-17}$ These cases indicate the potential for donors to have rights to deal with their tissue under both contract and tort law.

This broader recognition of property rights is a challenge to those who see human tissue donation as a form of gift that is devoid of proprietary rights. Indeed, the very notion of a gift in law is a property relationship where property passes hands without payment. Gifts can be given without conditions attached, but property law also recognises that gifts can be made conditionally in ways that preserve some rights of control and access for the donor.

Property law may be very useful in regulating cord blood banking because it creates a language for understanding conditional donation. Property laws may help to explain how cord blood could be gifted to a public bank on the condition that the donor parent(s) have the option to withdraw donated cord blood should the donor child or their sibling require the cord blood for their own medical use, and on the condition that the family are contacted before the cord blood is used in treatment or research (which is standard practice in some public banks). Property law also provides a model for understanding how, in the private banking context, a relative (such as a grandparent) could pay for the banking on the grounds that it is made available to a range of family members through a form of discretionary trust.

We believe that the current practice in the private banking industry has already effectively adopted property forms. The contracts for storage are bailments. The contracts also treat the cord blood as being held on behalf of an individual child or on behalf of the family group. This idea of holding property for the benefit of another is clearly a trust, where the legal title (held normally by the parents) is exercised for the benefit of the child (or family group). Once the child turns 18 years of age, most Australian 
contracts then state that the property then passes to the (now adult) child, which is again a classic trust mechanism.

In public banking, there appears to be more reticence to adopt property language, arguably because of its non-commercial focus. We argue that a public bank works just like a charitable trust - holding valuable property for the public benefit in pursuit of the charitable aims of improved health care. The usefulness of charitable trust laws is that they create a framework for donation and use of the cord blood.

While we recognise that property law is not a panacea for all regulatory woes, it does have the potential to provide tools for unpacking cord blood banking, as it provides a well established mechanism for recognising rights and resolving disputes between different interest holders.

\section{Private, public or hybrid banking?}

The complex issues surrounding cord blood banking and donation are not simply a function of the uncertain legal status of cord blood; they are also a function of the structure and function of public and private banks. Traditionally, public banks have stored donated cord blood for public use in allogeneic transplant programs and some (limited) types of research, while private banks have focused on storage for autologous treatment for the child donor. However, the line between public and private banking is becoming increasingly blurred. ${ }^{5}$ Many private banks now offer cord blood to matched family members of the child and are becoming increasingly involved in research projects. Public cord blood banks have generally acceded to requests to release donated CBUs for autologous transplantation or for use in related donor transplantation. But although there has been some convergence of practice, requests to use CBUs that have been donated to public banks to support allogeneic transplantation programs for research are more challenging. ${ }^{18}$

While those with opposing perspectives often build walls to protect their interests, this is unlikely to provide the best approach to accommodating both public and personal interest in cord blood. Indeed, the tensions that currently exist are likely to increase if the indications for autologous transplantation expand, or if evidence emerges that cord blood stem cells may have a therapeutic role outside of transplantation - be that in regenerative medicine or in immunoprotection against non-communicable diseases. As Han and Craig point out in this issue of the Journal, $^{18}$ it is becoming increasingly clear that policy is needed to deal with requests for the release of cord blood for therapeutic and research purposes from public banks. Serious consideration needs to be given to hybrid models of banking that offer both public donation and private banking or make privately stored CBUs available to the public system should they be needed for transplantation. ${ }^{5}$

\section{Conclusion}

Cord blood banking is a challenging area to regulate. It throws up unique problems of consent and is complicated by a dual system of public and private banking. The emergence of property rights in human tissue is a further complication, but one that we feel will ultimately provide a means of untying some of these difficult questions and resolving the disputes that will inevitably arise concerning this valuable resource. Regardless of the way forward, it is clear that any regulation should be developed in an open and transparent manner. Regulation should be drafted in light of the concerns of both public and private banking and should be based on well informed public debate. ${ }^{19}$ We welcome efforts by AusCord and the Australian Bone Marrow Donor Registry to address these issues and believe that there is much to be gained from a broader public discussion about the goals of medicine and research and the importance of community and social solidarity.

Acknowledgements: This article is part of a study funded by the National Health and Medical Research Council (project grant 512416): Ethical and legal issues surrounding the decision-making process for donating and banking umbilical cord blood.

Competing interests: Lorena Aparicio is an employee of the Australian Bone Marrow Donor Registry.

Provenance: Commissioned; externally peer reviewed.

1 Waldby C, Mitchell R. Tissue economies: blood, organs, and cell lines in late capitalism. New York: Duke University Press, 2006.

2 Stewart C, Kerridge I. Umbilical cord blood banking and the next generation of human tissue regulation: an agenda for research. J Law Med 2012; 19: 423-429.

3 Gluckman E, Ruggeri A, Volt F, et al. Milestones in umbilical cord blood transplantation. Br J Haematol 2011; 154: 441-447.

4 Ballen KK. Collection and preservation of cord blood for personal use. Biol Blood Marrow Transplant 2008; 14: 356-363.

5 O'Connor MA, Samuel G, Jordens CF, Kerridge IH. Umbilical cord blood banking: beyond the public-private divide. J Law Med 2012; 19: 512-516.

6 Waldby C. Umbilical cord blood: from social gift to venture capital. BioSocieties 2006; 1: 55-70. doi: 10.1017/S1745855205050088.

7 Querol S, Gomez SG, Pagliuca A, et al. Quality rather than quantity: the cord blood bank dilemma. Bone Marrow Transplant 2010; 45: 970-978.

8 Rebulla P, Lecchi L. Towards responsible cord blood banking models. Cell Prolif 2011; 44 Suppl 1: 30-34.

9 NSW Health. Review of the Human Tissue Act 1983. Blood donation and the supply of blood and blood products. April 2002. http://www.health.nsw.gov.au/ resources/aboutus/legal/bloodreport.asp (accessed Oct 2012).

10 Jordens CF, O'Connor MA, Kerridge IH, et al. Religious perspectives on umbilical cord blood banking. J Law Med 2012; 19: 497-511.

11 Sugarman J, Reisner EG, Kurtzberg J. Ethical aspects of banking placental blood for transplantation. JAMA 1995; 274: 1783-1785.

12 Hardcastle R. Law and the human body: property rights, ownership and control. Oxford: Hart Publishing, 2007.

13 Goold I. Sounds suspiciously like property treatment: does human tissue fit within the common law concept of property? UTS Law Rev 2005; 7: 62. http:// worldlii.austlii.edu.au/au/journals/UTSLRev/2005/3.html (accessed Jun 2013).

14 Skene L. Legal rights in human bodies, body parts and tissue. J Bioeth Inq 2007; 4:129-133.

15 Yearworth v North Bristol NHS Trust [2009] EWCA Civ 37. http://www.bailii.org/ ew/cases/EWCA/Civ/2009/37.html (accessed Jul 2013).

16 Bazley v Wesley Monash IVF Pty Ltd [2010] QSC 118. http://www.sclqld.org.au/ qjudgment/2010/QSC/118 (accessed Jul 2013).

17 Jocelyn Edwards; Re the estate of the late Mark Edwards [2011] NSWSC 478. http://www.caselaw.nsw.gov.au/action/PJUDG?jgmtid=152086 (accessed Jul 2013)

18 Han MX, Craig ME. Research using autologous cord blood - time for a policy change? Med J Aust 2013; 199: 288-289.

19 Weisbrot D. The ethical, legal and social implications of umbilical cord blood banking: learning important lessons from the protection of human genetic information. J Law Med 2012; 19: 525-549. 